\title{
PARADIGMAS DE INTERPRETAÇÃO CONSTITUCIONAL: DESAFIOS AO ENTENDIMENTO DAS SOCIEDADES MODERNAS
}

\author{
Daniel Barile da Silveira ${ }^{1}$
}

\begin{abstract}
RESUMO: O constitucionalismo moderno trouxe consigo para a contemporaneidade complexas questões consoante às diversas formas de entendimento de um texto constitucional, o que levou a uma "crise de sentido" dos comandos trazidos pela Constituição. Em R. Dworkin, a compreensão da Constituição como integridade é peça central na estruturação de uma sociedade aberta e plural de indivíduos que se consideram mutuamente iguais. É dessa comunidade que emanam princípios, sempre compreendidos como normas, e não como valores. Ante esse pano de fundo, o presente trabalho visa a demonstrar qual a inadequabilidade de se entender uma comunidade não como sendo constituída por princípios, mas como se fosse uma "ordem concreta de valores" (R. Alexy), demonstrando quais os riscos que tal concepção carrega e como tal proposta gera elementos inadequados para esse paradigma do constitucionalismo.
\end{abstract}

PALAVRAS-CHAVE: Constituição, Princípios, Robert Alexy, Ronald Dworkin.

\section{Constitutional interpretation paradigms: understanding modern societies}

\begin{abstract}
Modern constitutionalism has brought itself to the current ages difficult questions about constitutional interpretation, which denotes a "crisis of sense" into the juridical discussion of how to conceive and interpretate the constitutional law commands. R. Dworkin established a paradigm which concerns in conceiving the Constitution as integrity, extremely important to solve numerous problems of our complex society. In other hand, R. Alexy understands Constitution as a order of values, which brings a new conception of the whole constitutional hermeneutics. The present article intends to confront these paradigms and search for a respected solution into the modern juridical debate.
\end{abstract}

KEY-WORDS: Constitution, Principles, Robert Alexy, Ronald Dworkin.

\footnotetext{
${ }^{1}$ Mestrando em Direito do Estado pela Universidade de Brasília (UnB). E-mail: danielbarile@ hotmail.com.
} 


\section{Introdução}

Segundo Pierre Clastres (1990), as sociedades inventam leis, símbolos e regras e, inadvertidamente, acabam ficando presas a elas. Neste mesmo sentido, Max Weber, com extrema sutileza própria de seu pensamento voltado ao contínuo processo de racionalização das estruturas sociais, simboliza tal compreensão ao preconizar que a razão humana, levada em suas últimas instâncias de desmistificação da vida prática moderna, encerra em sua lógica uma indelével "jaula de ferro" (1999, último capítulo), ou seja, engendra uma sorte de encarceramento de toda vida social, mormente produzida pelo atávico comportamento dos indivíduos de sempre buscar transformar nossa vivência mundana em um emaranhado de categorias de pensamento e de prescrição de comportamento e de valores, cujo deslinde se demonstra empiricamente de difícil constatação.

A tradição do pensamento jurídico positivista dos novecentos é uma demonstração fática de tais assertivas. O Positivismo Jurídico, enquanto doutrina paradigmática que marcou uma ruptura com a ordem tradicional de cariz consuetudinário, ou de magificação e revelação do Direito interpretado das sagradas escrituras, trouxe consigo a concepção de que o critério do justo e da submissão às ordens políticas da autoridade apenas poderiam ser efetivadas se normas gerais e abstratas pautassem o comportamento dos indivíduos em suas relações privada e pública. Instaurando o reino da norma laicizada como o único mecanismo de prescrição de condutas pela autoridade política de forma universalmente válida, os indivíduos lentamente se depararam com uma gradual alteração das estruturas sociais, sendo que, recém desligados dos laços de tradição que organizavam suas vidas na medievalidade, verificava-se, à luz do que pregavam os positivistas clássicos, que seus comportamentos sofreriam uma intensa e paulatina regulamentação jurídica de toda sorte, abrangendo praticamente todas as áreas do comportamento humano.

Neste sentido, a existência de leis que ordenassem a vida coletiva tornou-se, com a consolidação do pensamento positivista, requisito essencial para a implantação da ordem e paz sociais em uma dada associação política. Com tal visão em voga, a simples forma da lei vigente garantiria que sua observância estrita desencadeasse conseqüentemente a satisfação da regra da Justiça: comportamento conforme à lei $=$ justo/ contrário à lei $=$ injusto. Hans Kelsen, maior expressão dessa corrente teórica, defendia que todo comportamento humano pode ser reduzido a uma relação binária de "permitido-proibido", tendo como referencial a 
subsunção dessas determinadas condutas àqueles preceitos formalmente prescritos em $1 \mathrm{ei}^{2}$. A forma do Direito, consubstancializada na mera existência de um ordenamento válido no cerne do sistema jurídico de um povo, revelava-se, destarte, como um fim em si mesmo, bastando sua imediata imposição pela autoridade estatal, não importando quem fosse este governante responsável pela produção normativa (FIORAVANTI, 2001, p. 155). Para Kelsen e para todo positivismo clássico, o Direito poderia ser produzido por qualquer autoridade, sendo a questão da forma da lei a única observância para a garantia de sua validade.

E nesta seara é que a concepção de Estado de Direito Moderno surge como fruto desse movimento, tendo a ordenação legal refletida na supremacia da Constituição seu nascituro mais imediato. Conforme nos lembrou com muita acurácia Niklas Luhmann (1996), com o advento da modernidade, Direito e Estado encontram-se permanentemente ligados, tendo a Constituição o ponto de convergência que acopla estruturalmente Direito e Política, permitindo tanto o reconhecimento da legitimidade do poder do governante em ser obedecido pelos indivíduos, bem como fornece o critério de validade das normas jurídicas, submetidas estas a um arquétipo hierarquizado em que a própria Constituição se encontra no ápice da estrutura desse sistema. Nesta conjuntura, portanto, é com a Constituição que se é permitida a autoridade impor legalmente seus mandamentos a toda uma coletividade, sendo, ademais, um instrumento de compreensão e de validade de todo o arcabouço jurídico, peça fundamental de estruturação das sociedades hodiernas.

Como se pode perceber, Direito e Estado nascem teoricamente quase de uma unção unívoca da existência de um ordenamento jurídico formal que lhes dêem organização institucional e legitimidade. A existência de uma ordem legal assentada em bases formalconstitucionais representou na modernidade uma insígnia de importância fundamental para instaurar toda sistemática jurídica, constituindo também peça-chave para a subsistência de um sistema de dominação político dotado de legitimidade, importante para a asserção de determinados direitos e valores reivindicados na época.

Ocorre que a tradição legada pelo positivismo jurídico trouxe-nos sérias consequiências ao devotarmos suprema validade a textos legais formalmente concebidos, especialmente no

\footnotetext{
2 "Quando uma norma estatui uma determinada conduta como devida (no sentido de 'prescrita'), a conduta real (fática) pode corresponder à norma ou contrariá-la. Corresponde à norma quando é tal como deve ser de acordo com a norma; contraria a norma quando não é tal como, de acordo com a norma deveria ser, porque é o contrário de uma conduta que corresponde à norma. [...] Uma norma objetivamente válida, que fixa uma conduta como devida, constitui um valor positivo ou negativo. A conduta que corresponde à norma tem um valor positivo, a conduta que contraria a norma tem um valor negativo" (2000, p. 18-9)
} 
que toca a como lidar não apenas com a forma da lei - que certamente é fundamental para a estruturação de nossa sobrevivência coletiva -, mas se mostrou imprescindível também se reclamar pela apreensão do conteúdo expresso no corpo desses estatutos legais, especialmente tratando-se da Constituição de um Estado, como sendo uma forma lídima de efetivamente garantir direitos em meio a uma sociedade complexa de cariz contemporâneo.

Neste ponto reside, em especial, a problemática da interpretação constitucional. Sob a perspectiva do paradigma positivista em um Estado de Direito, sucintamente descrito anteriormente, como bem nos ensina Menelick de Carvalho Neto, a atividade hermenêutica tem a característica, por essência, de ser uma atividade de compatibilização da norma com a realidade fática, através de um processo automático de subsunção, "uma atividade mecânica resultante da leitura dos textos que deveriam ser claros e distintos" (1998, p. 24). Ao juiz, nestes casos, reserva-se apenas a única tarefa de ser mera "bouche de loi" (1998, p. 24).

Com o advento das sociedades contemporâneas (ou pós-modernas - a acepção conceitual é indiferente para os fins aqui propugnados), como sendo sociedades complexas por excelência, a existência formal de uma Constituição, bem como sua aplicação estrita e vinculada a uma subsunção "mecânica" não se faz necessário para a solução dos problemas surgidos, reclamando-se por novas formas de compreensão de como solucionar os conflitos sociais. Daí o pensamento jurídico conceber a Constituição não apenas como normas estritamente consideradas, mas como um conjunto de princípios e normas que irão ter aplicabilidade no deslinde dos casos práticos, o que não raro suscitam problemáticas profundas para o enfrentamento das situações cotidianas. Nesta conjuntura, toda solução litigiosa constitui um caso de difícil decisão (hard case), sendo que, sob o paradigma do Estado Democrático de Direito, regras e princípios colidem-se e competem entre si para a solução do caso concreto.

\section{A perspectiva de Alexy - A Constituição como uma ordem de valores}

Conforme Robert Alexy preconiza, as Constituições democráticas modernas possuem em seu bojo, como fundamentos constituintes do núcleo duro dos direitos individuais, dois componentes essenciais para o entendimento da interpretação constitucional: de um lado, as regras, aplicáveis a todo sistema jurídico; e, por um outro lado, os princípios, de "construção extensa e holística" (2003, p. 132), que se difundem no interior de uma dada ordem jurídica. Em sua concepção - e aqui é importante frisar - os princípios integram a Constituição em sua 
essência como “uma ordem objetiva de valores" (2003, p. 132), estando estes sempre em constante colisão. Conforme assevera, "toda colisão ente princípios pode expressar-se como uma colisão entre valores e vice-versa", complementando que "princípios e valores são para tanto o mesmo, contemplando um caso sob um aspecto deontológico, e no outro sob um aspecto axiológico" (1998, 145, tradução nossa).

Sob tal perspectiva, Alexy entende que, levando-se em conta que a Constituição nos é apresentada como uma ordem concreta de princípios, que nada mais são do que valores objetivamente considerados em última instância, o único mecanismo de se solucionar as questões postas seria a de escolher qual valor possui mais peso, qual princípio que sobressalta no caso concreto. Deste modo, como valores e princípios tendem a colidir constantemente, sua resolução apenas pode ser efetuada a partir do "balanceamento" ou "ponderação" dessa tensão. Para o deslinde das situações fáticas, na visão de Alexy, seria necessário "um balanceamento de interesses" (2003, p. 134), permitindo ao órgão julgador decidir um caso difícil da melhor maneira possível. Em sua obra mais conhecida, "Teoria dos Direitos Fundamentais", esclarece que:

As colisões de princípios devem ser solucionadas de maneira totalmente distinta. Quando dois princípios entram em colisão - tal como é o caso quando segundo um princípio algo está proibido e, segundo outro princípio, está permitido - um dos princípios tem que ceder ante o outro. Porém, isto não significa declarar inválido o princípio desprezado nem que no princípio desprezado há que introduzir uma cláusula de exceção. Mas bem o que sucede é que, sob certas circunstâncias um dos princípios precede ao outro. Sob outras circunstâncias, a questão da precedência pode ser solucionada de maneira inversa. Isto é o que se quer dizer quando se afirma que nos casos concretos os princípios têm diferente peso e que prevalece o princípio com maior peso. Os conflitos de regras se levam a cabo na dimensão da validez; a colisão de princípios - como só podem entrar em colisão princípios válidos - tem lugar além da dimensão da validez, na dimensão do peso (1997, p. 89, tradução e grifos nossos).

Esta perspectiva lançada por Alexy suscitou inúmeras controvérsias no âmbito jurídico. Ao tratar como uma ordem "concreta de valores" a Constituição, devendo os casos práticos ser solucionados por intermédio da ponderação, Alexy acaba levando sua argumentação a problemas extremamente delicados quando analisada a sistemática jurídica em uma sociedade complexa. Uma das peculiaridades essenciais de acepção desse pensamento se dá sob a perspectiva de que, ao se tratar princípios como valores, ponderando-os para encontrar-se a solução adequada ao caso concreto, ao descermos do nível da abstração teórica para a prática, 
verifica-se que a multiplicidade e o antagonismo de valores acabam por transformar a decisão judicial em um artifício arbitrário por excelência. Como em cada magistrado residem concepções diferentes da realidade social, um valor possui mais valor do que outro em seu íntimo, vislumbrando na questão prática diferentes hierarquizações axiológicas impossíveis de serem objetivadas universalmente. Nestes casos, abrir-se-ia uma janela fecunda para o extravasamento da subjetividade, o que deveras exsurge como pano de fundo o questionamento sobre a própria racionalidade desse procedimento decisório. Como consequiência lógica, um princípio excluiria o outro, trazendo graves incoerências na vida cotidiana. Ademais, se partirmos do princípio que uma colisão entre princípios deve ser dirimida a partir de seu balanceamento, apenas poderemos ponderá-los se os concebermos em seu ponto ótimo, em sua maximização, o que inviabiliza na prática sua validade como veículo de aplicação. Isto se justifica na medida em que, como se verifica empiricamente, tais princípios sofrem interferências e minimizações por outros princípios, quase nunca se vislumbrando a otimização de princípios, como quer Alexy. Assim entendido, o conteúdo normativo dos princípios acaba não recebendo a devida atenção, esvaziando o texto da Constituição dessa força mandamental.

Jüngen Habermas enfrentou este último problema com maior ênfase. Conforme entendia, o fato de se considerar a Constituição como receptáculo de princípios entendidos como valores, devendo se resolver as questões surgidas a partir de suas colisões por intermédio do balanceamento, encerra em sua origem, necessariamente, o enfraquecimento do conteúdo deontológico desses princípios. Habermas asseverava que

[...] se princípios manifestam um valor que deve ser realizado da melhor forma possivel, ou seja, otimizado, e se as próprias normas não regem a extensão, a medida, em que se deve cumprir essa prescrição de otimização, a aplicação de tais princípios nos limites do que é faticamente possível torna necessária uma ponderação voltada para os fins, para os objetivos (apud ALEXY, 2002, p. 388).

E continua na argumentação ao afirmar que este objetivo colimado em proceder ao balanceamento orientado aos fins "permite que direitos individuais sejam sacrificados a finalidades coletivas" (2002, p. 388). Tal lógica faria com que os princípios perdessem sua força normativa, fato que apenas poderia ser sanado se tratarmos os princípios não como valores, mas como regras. 
Um outro ponto combatido por Habermas reside na questão da irracionalidade da decisão submetida ao procedimento do balanceamento. Como não existiriam padrões racionais para a ponderação, este procedimento apenas poderia ser efetivado se uma certa dose de subjetividade do órgão julgador atuasse no caso concreto, o que proporcionaria julgamentos múltiplos. Tal sistema torna-se, no mínimo, instável. Princípios e valores, sustenta Habermas, não podem se confundir, posto que aqueles assumem caráter normativo no julgamento dos casos concretos. Assim dizia:

O código de preceitos que distingue o certo do errado (right and wrong), tal como analogamente o que discerne a verdade da falsidade, e a correspondente incondicionalidade da pretensão de validade normativa vinculada a tais preceitos não é afetada se se limita a esfera de validade a uma determinada comunidade jurídica. A lei, o Direito, ainda confronta os seus destinatários com uma pretensão de validade que não permite que os direitos sejam "sopesados" como se fossem "valores jurídicos" com distintos graus de prioridade. A forma como nós avaliamos nossos valores e decidimos o que é "bom para nós" e o que é "melhor," em uma dada época, muda todos os dias. No momento em que reduzimos o princípio da igualdade jurídica a um simples bem dentre outros, direitos individuais podem vir a ser por vezes sacrificados a finalidades coletivas. Assim resulta que não podemos ver como um direito poderia se submeter a outro (we do not see that one right can yield to another right), sem perda de validade, quando os dois eventualmente conflitem (HABERMAS, 1996, p. 19).

Por fim, Habermas ainda critica a posição defendida por Alexy no que toca ao processo de justificação das decisões proferidas pelo magistrado. Ao se tratar da resolução da colidência de princípios através de um mecanismo de ponderação destes, automaticamente se retiraria de maneira definitiva as decisões da relação dúplice própria do Direito, consistente no binômio "certo-errado" ("correção-incorreção"), mudando-as para conceitos como "adequadoinadequado", campo correspondente à descrição (ALEXY, 2003, p. 135). Deste modo, não basta descrever a aplicação de princípios em um caso dado a partir de ponderações, porém essencialmente deve-se justificá-los, indicando não um juízo em relação ao "resultado" mas todo seu processo justificativo (ALEXY, 2003, p. 135).

Tais críticas de Habermas produziram um profundo debate sobre como conceber o Direito organizado segundo ordens de valores em meio a sociedades complexas, trazendo problemas consigo de maneira a se repensar não só as contribuições do paradigma positivista, mas promovendo uma efetiva releitura da teoria constitucional com vistas a se buscar melhores critérios para o encontro de uma decisão mais justa no enfrentamento das questões práticas. 


\section{A perspectiva de Dworkin - A Constituição como uma ordem de princípios}

A mais contundente teoria que obteve maior êxito na contestação da idéia de se conceber a Constituição como uma ordem concreta de valores, contrariando o pensamento de Alexy, foi sem dúvida a de Ronald Dworkin. Segundo tal pensador, em uma Constituição concebida sob a égide do paradigma do Estado Democrático de Direito, tanto os princípios quanto as regras devem necessariamente ser entendidos como normas, jamais como valores. Em sua visão, a Constituição é composta por um sistema de regras e princípios que adotam caráter de força normativa, sendo que se distinguem pela característica de que as primeiras são aplicadas em um binômio de "tudo ou nada", enquanto que os segundos podem sobreviver perfeitamente na solução de um caso concreto, sem que haja a necessidade de um excluir o outro. Enquanto que em um ordenamento jurídico as regras não admitem seus opostos, por um outro lado, os princípios permitem essa conciliação sem que haja a supressão de um ou de vários deles para a exsurgência de outro(s) quando da análise de uma situação corrente.

O ponto de partida de Dworkin se mostra viável a resolver a problemática suscitada sobre o conceito de ponderação de Alexy na medida em que aquele autor visa demonstrar como se obter um certo grau de racionalidade na solução de questões jurídicas com recorrência aos princípios. Para Dworkin, a atividade jurisdicional deve buscar basicamente não um mecanismo de "ponderação" ou "balanceamento" de princípios para se chegar a uma solução plausível, objetivando aplicar o princípio de maior peso, mas deve estar pautada fundamentalmente por uma sentido que permita a coexistência de diversos princípios - próprio de uma sociedade plural e complexa como a contemporânea -, sem que se perca, em contrapartida, a "certeza" do Direito, correspondente aos sensos de segurança da ordem jurídica e de efetivação da Justiça.

Conforme o pensamento jurídico herdado de Klaus Günther, Dworkin vai adotar a concepção de que existe uma profunda divisão nas atividades legislativa e judiciária. Enquanto que na atividade legislativa há uma forte predominância de seu caráter justificativo - marcado pela generalidade, abstração e universalidade em relação à produção de leis que são válidas erga omnes, e por isso são normas que não possuem a previsão explícita de todos os comportamentos na lei abstratamente prescritos -, o mister jurisdicional assume um cariz de concretude e irrepetibilidade, posto que cada caso é único, historicamente singular, marcado 
por seu caráter de aplicabilidade a um dado caso sub judice (ALEXY, 1993) ${ }^{3}$. Daí o porque, na visão concebida por Dworkin, a tarefa primordial do magistrado é de verificar no caso concreto que norma é aplicada a cada caso, em um processo de interpretação de princípios e revisão de todo texto com vistas a se buscar uma única decisão aplicável. Nesta visão, cada caso é um caso único, devendo ser tratado sempre como um hard case.

Para se constatar uma lídima aplicação do direito ao caso posto sob a tutela jurisdicional do Estado, Dworkin propõe que o Direito deve ser entendido como uma ordem de princípios, marcada pela sua "integridade". Cada decisão judicial deve ser considerada válida conquanto reduza a complexidade do Direito e sua conseqüente indeterminação conforme esteja pautada pela reconstrução que o magistrado realiza da ordem jurídica, determinando qual a norma aplicável ao caso conforme um conjunto de princípios extraídos desse sistema íntegro. Neste sentido, na concepção de Dworkin, o magistrado não pode pender para a discricionariedade no caso de a norma não ser clara o suficiente para o deslinde das situações práticas, diferentemente como pregava a doutrina positivista em seu ápice, mais especificamente vislumbrada no caso de seu antecessor, H. Hart. Ao juiz não é legítimo ditar normas, função esta própria da esfera legislativa. A incerteza do Direito deve ser compensada por critérios utilizados pelo magistrado que justifiquem sua tomada de decisão de forma consistente com o sistema jurídico como um todo. Trata-se de uma "interpretação construtiva", como bem nos ensina Vera Karam de Chueiri (1997, p. 182). Assim afirma Dworkin:

Estabeleci uma distinção entre duas formas de integridade ao arrolar dois princípios: a integridade na legislação e a integridade na deliberação judicial. A primeira restringe aquilo que nossos legisladores e outros participantes da criação do direito podem fazer corretamente ao expandir ou alterar nossas normas públicas. A segunda requer que, até onde seja possível, nossos juízes tratem nosso atual sistema de normas públicas como se este expressasse e respeitasse um conjunto coerente de princípios e, com esse fim, que interpretem essas normas de modo a descobrir normas implícitas entre e sob as normas explícitas. Para nós, a integridade é uma virtude ao lado da justiça e da eqüidade (fairness) e do devido processo legal, mas isso não significa que, em algumas das duas formas assinaladas, a integridade seja necessariamente, ou sempre, superior a outras virtudes. O legislativo deveria ser guiado pelo princípio legislativo da integridade, [...]

\footnotetext{
${ }^{3}$ Conforme nos ensina Menelick de Carvalho Netto, “[...] A sensibilidade do juiz para as especificidades do caso concreto que tem diante de si é fundamental, portanto, para que possa encontrar a norma adequada a produzir justiça naquela situação específica. É precisamente a diferença entre os discursos legislativos de justificação, regidos pelas exigências de universalidade e abstração, e os discursos judiciais e executivos de aplicação, regidos pelas exigências de respeito às especificidades e à concretude de cada caso, ao densificarem as normas gerais e abstratas na produção das normas individuais e concretas, que fornece o substrato que Klaus Günther denomina senso de adequabilidade, que, no Estado Democrático de Direito, é de se exigir do concretizador ao tomar suas decisões" (1998, p. 39).
} 
[sendo que] nunca deve, sejam quais forem as circunstâncias, tornar o direito mais incoerente em princípio do que ele já é. [...] O princípio da integridade na prestação da justiça não é de modo algum superior ao propósito do que os juízes devem fazer cotidianamente. Esse princípio é decisivo para aquilo que um juiz reconhece como direito. Reina, por assim dizer, sobre os fundamentos do direito [...]. O juiz que aceitar a integridade pensará que o direito que esta define estabelece os direitos definitivos que os litigantes têm a uma decisão dele. Eles têm, em princípio, de ter seus atos julgados de acordo com a melhor concepção daquilo que as normas jurídicas da comunidade exigiam ou permitiam na época em que se deram os fatos, e a integridade exige que essas normas sejam consideradas coerentes, como se o Estado tivesse uma só voz. (2003, p. 261-3)

Tais pensamentos nos remetem a uma reflexão importante sobre os rumos que o constitucionalismo tem tomado neste último século. Ao conceber o Direito como uma ordem de princípios, Dworkin afasta terminantemente a tese de Alexy ao repousar tal concepção como uma ordem concreta de valores (base teórica da chamada "jurisprudência de valores"). O pano de fundo que permeia sua obra, sem dúvida, estabelece-se na certeza do Direito, essencial para se garantir a construção de uma associação política organizada e crente na realização da Justiça em meio à sempre crescente complexidade social ${ }^{4}$.

Um ponto que se pode levantar para desautorizar a praticidade de se conceber uma teoria da Constituição como sendo formada por uma ordem concreta de valores se dá no caso de entender os princípios como comandos "otimizáveis". Essa concepção alexyana, conforme demonstrado anteriormente, acaba por resultar no fato de que, em uma colisão de princípios, como resultado, um deve prevalecer sobre o outro - através do balanceamento para se determinar aquele que possui maior peso -, sendo que a coexistência destes não ganha lugar em sua teses. Como conseqüência mais próxima, vislumbra-se que o exercício regular de um direito atribuído a uma pessoa pode colidir com este mesmo exercício efetuado por outro indivíduo. Nesta conjuntura, difícil seria distinguir o abuso de direito, bem como o sistema de princípios entraria em um paradoxo profundo conquanto a como proceder a uma ponderação racional que não seja desvirtuada como uma decisão irracional por princípio, especialmente

\footnotetext{
${ }^{4}$ Já dizia Habermas em "Faticidade e Validade" ao analisar a vigência do paradigma da jurisprudência de valores no seio das argumentações da Suprema Corte Alemã: "Tal jurisprudência de valores levanta realmente o problema da legitimidade, que Maus e Böckenförde analisam, tomando como referência a prática de decisão do Tribunal Constitucional Federal. Pois ela implica um tipo de concretização de normas que coloca a jurisprudência constitucional no estado de uma legislação concorrente. [...] Ao deixar-se conduzir pela idéia da realização de valores materiais, dados preliminarmente no direito constitucional, o Tribunal constitucional transforma-se numa instância autoritária. No caso de uma colisão, todas as razões podem assumir o caráter de argumentos de colocação de objetivos, o que faz ruir a viga mestra introduzida no discurso jurídico pela compreensão deontológica de normas e princípios do direito. [...] $\mathrm{Na}$ medida em que um tribunal constitucional adota a doutrina da ordem de valores e a toma como base de sua prática de decisão, cresce o perigo dos juízos irracionais, porque, neste caso, os argumentos funcionalistas prevalecem sobre os normativos" (1997, 320-2).
} 
ante a dificuldade de se afastar o elemento subjetivo quando da solução do confronto de direitos. A ponderação, aqui, remontando a Dworkin, deve focar não nos direitos, em qual um deve prevalecer em detrimento do outro, porém atém-se aos argumentos, revelando qual o melhor caminho para se decidir o caso concreto sem que haja prejuízo para ambas as partes litigantes.

Um outro problema já comentado e que se mostra de fundamental importância para o entendimento de um constitucionalismo compatível com as exigências sociais de um Estado Democrático de Direito é de que, ao entendermos o sistema jurídico a partir de um ponto de vista axiológico, constituindo princípios como valores propriamente ditos, cai-se em um grave risco por não se observar tanto a pluralidade de hierarquização desses valores pelos indivíduos, bem como reduz toda complexidade social a uma mera contingência de valores universalizáveis por uma dada sociedade. Melhor explicando, como os direitos estão vinculados a valores e estes brotam da formação cultural de uma dada comunidade política, ao considerar estes como critérios determinantes do que é justo/injusto, certo/errado, acaba-se por sufocar a vontade do indivíduo em constituir seu projeto existencial de forma diversa dos valores estabelecidos por essa sociedade. Como vivemos em uma sociedade pluralista, formada por diversas crenças, valores e concepções de vida, definir direitos de forma universal com referência a valores que pesam mais que outros, destrói com qualquer possibilidade de afirmação do indivíduo enquanto ser dotado de liberdade de escolha, pois vincula seus direitos com o senso geral da sociedade sobre uma hierarquia de valores pré-fixada. Cada pessoa, assim, tem direito de desenvolver-se sem a interferência da sociedade, e a visão preconizada por Alexy, por exemplo, vai de encontro com essa problemática.

\section{Conclusão}

Assim entendido, tais questões são suscitadas ao se entender a Constituição como uma ordem de valores universalmente válidos. Os riscos de se levar tal pensamento às últimas conseqüências certamente vem em desalinho com os reclamos de uma sociedade complexa pela certeza do direito e pela satisfação justiça nos casos levados a juízo. O paradigma do Estado Democrático de Direito requer, para sua própria subsistência, uma pluralidade de valores regentes na tessitura social que, quando postos em confronto na esfera judicial, não desencadeiem o aniquilamento de uns para a glória suprema de outros, o que traria como consequiência o perigo da concretização oficial de sérias injustiças soberanamente oficializadas 
pelos órgãos de Estado. A crença da segurança jurídica requer um mínimo de racionalidade procedimental no deslinde de controvérsias pelos órgãos julgadores, buscando sempre a mais justa adequação dos códigos aos fatos. Caso contrário, havendo prevalência de decisões "mecânicas", conforme se depreende do modelo positivista, ou ainda axiológica da jurisprudência de valores, cairíamos no sério risco de se engessar nossos direitos, submetendoos à indevassável "cela de ferro" da insensibilidade jurisdicional e permitindo fenecer os ideais de justiça de uma comunidade pós-moderna.

\section{Referências Bibliográficas}

ALEXY, Robert. Direitos fundamentais, balanceamento e racionalidade. In: Ratio Juris, v. 16, n. 2, jun. Trad. Menelick de Carvalho Netto, 2003, p. 131-40.

Justificação e aplicação das normas. In:Ratio Juris, v. 6, n. 2, jul.,1993, p.157-70.

Sistema jurídico, principios jurídicos y razón práctica. In: Doxa, v. 5, 1988, p. 139-

51.

. Teoría de los derechos fundamentales. Madrid: Centro de Estudios Constitucionales, 1997.

Uma teoria dos direitos constitucionais. In: A theory of constitutional rights. Trad. Julian Rivers. Pósfácio. Oxford/New York: Oxford University Press, 2002, p. 288-425.

CARVALHO NETTO, Menelick de. Hermenêutica constitucional sob o paradigma do Estado Democrático de Direito. In: Revista Notícia do Direito Brasileiro, v. 6, jul./dez. Brasília: Fundação Universidade de Brasília, 1998, p. 25-44.

CHUEIRI, Vera Karam de. A dimensão jurídico-ética da razão: o liberalismo jurídico de Dworkin. In: Paradoxos da auto-observação: percursos da teoria jurídica contemporânea. Curitiba: JM Editora, 1997, p. 153-95.

CLASTRES, Pierre. A sociedade contra o estado. 5. ed. Rio de Janeiro: Francisco Alves, 1990.

DWORKIN, Ronald. O império do direito. cap. 6 e 7. São Paulo: Martins Fontes, 2003, p. 213-331.

FIORAVANTI, Maurizio. Constitución: dela antiguedad a nuestros dias. Madrid: Trotta, 2001.

HABERMAS, Jürgen. Direito e Democracia: entre faticidade e validade. Rio de Janeiro: Tempo Brasileiro, 1997. 
Resposta aos participantes do simpósio no Benjamin N. Cardozo School of Law. Trad. William Regh. In: Cardozo Law Review, n. 17, mar., 1996, [1-34].

KELSEN, Hans.Teoria pura do direito. 6. ed. São Paulo: Martins Fontes, 2000.

LUHMANN, Niklas. A constituição como aquisição evolutiva. In: ZAGREBELSKY, Gustavo; PORTINARO, Pier Paolo; LUTHER, Jörg. Il Futuro della Costituzione. Trad. Menelick de Carvalho Netto, Giancarlo Corsi e Raffaele De Giorgi. Notas de rodapé traduzidas da versão em italiano por Paulo Sávio Peixoto Maia (texto não revisado pelo tradutor). Torino: Einaudi, 1996.

WEBER, Max. A ética protestante e o espírito do capitalismo. 14. ed. Rio de Janeiro: Biblioteca Pioneira das Ciências Sociais, 1999. 